\title{
Evaluation of Retinal Nerve Fiber Layer and Ganglion Cell-Inner Plexiform Layer Loss in Patients with Primary Open Angle Glaucoma
}

\author{
Mohamed M Almbsut, Amira G Abdelhameed, Dalia S El-Emam and \\ Asaad A Ghanem* \\ Mansoura Ophthalmic Center, Faculty of Medicine, Mansoura University, \\ Mansoura, Egypt \\ *Corresponding Author: Asaad A Ghanem, Professor, Mansoura Ophthalmic Center, \\ Faculty of Medicine, Mansoura University, Mansoura, Egypt.
}

Received: May 07, 2020

Published: June 12, 2020

(C) All rights are reserved by Asaad A

Ghanem., et al.

\begin{abstract}
Aim: This study aimed to compare peripapillary retinal nerve fiber layer (RNFL) and macular retinal ganglion cell-inner plexiform layer (GC-IPL) changes in patients with primary open-angle glaucoma with control subjects by Swept Source optical coherence tomography.

Methods: This was a comparative cross-sectional study included 40 eyes of 40 POAG and 40 eyes of 40 control subjects. Ophthalmic examination, measurement of intraocular pressure, Visual field evaluation by using Humphrey (2003 Carl Zeiss Meditec, Germany) were done. All subjects were scanned using swept source Optical Coherence Tomography (Triton, Topcon, Tokyo, Japan) imaging to measure Macular GC-IPL thickness, peripapillary RNFL thickness.

Results: The mean age of the patients with POAG was $58.20 \pm 9.12$ years; 26 eyes (65.0\%) were male and 14 eyes (35.0\%) were female. The mean age of control subjects was $54.10 \pm 9.11$ years. The mean visual field MD was $-11.30 \pm 6.88 \mathrm{db}, \mathrm{SE}$ was $-3.43 \pm 1.08$ D, CMT was $164.3 \pm 16.62 \mathrm{Um}$ and IOP was $15.25 \pm 1.33 \mathrm{mmHg}$ in patients with POAG, whereas mean visual field MD was $-0.97 \pm 0.39$ $\mathrm{db}$, SE was $-3.23 \pm 1.04 \mathrm{D}$, CMT was $170.6 \pm 9.21 \mathrm{Um}$ and IOP was $13.20 \pm 1.18 \mathrm{mmHg}$ in control subject. A statistically significant difference of IOP, visual field MD was detected between the study groups with $p$ value $(p<0.001)$. the Mean Macular GC-IPL thickness and peripapillary RNFL thickness were significantly decrease in POAG patients when compared with controls $(\mathrm{p}<0.001)$.

Conclusion: Retinal nerve fiber layer and ganglion cell-inner plexiform Layer by Swept-source OCT showed statistically significant decrease in POAG patients.
\end{abstract}

Keywords: RNFL; Macular GC-IPL; OCT; POAG

\section{Introduction}

Glaucoma causes optic neuropathy in a progressive that is characterized by is characterized by loss of retinal ganglion cells (RGCs) and their respective axons [1]. In the evaluation of glaucoma, RNFL thickness assessment is relevant, because thinning of the RNFL is correlated directly with loss of ganglion cells, which is assumed to be a primary site of glaucomatous damage [2].

Progressive loss of the retinal ganglion cell axons in glaucoma can be objectively and reproducibly measured as progressive thinning of the retinal nerve fiber layer (RNFL) with optical coherence tomography (OCT) [3]. However, recent advances in OCT technology have enabled more detailed segmentation of the macular in- ner retinal layers, and thus allowed the quantitative evaluation of macular RGC damage [4].

Apoptosis of RGCs and their axons, the diagnostic of glaucoma, results not only in peripapillary RNFL thinning but also in thinning of the retina in the macular area. As approximately $50 \%$ of RGCs are concentrated within $4.5 \mathrm{~mm}$ of the fovea, alterations in macular structure are likely to be a good index of glaucoma-related neural damage. Recent studies have revealed that OCT measurements of macular structures such as macular ganglion cell complex (GCC) may be suitable for distinguishing healthy and glaucomatous eyes. Developments in OCT provide the ability for segmentation of the ganglion cell containing macular ganglion cell-inner plexiform layer (GCIPL). Macular GCC has been reported to have similar diagnostic performance to peripapillary RNFL [5]. 
Quantitative detection of glaucomatous damage at the posterior pole using retinal thickness mapping may provide a unique method for the early detection and monitoring of early glaucomatous tissue loss. However, ganglion cell complex (GCC) parameter has significantly higher diagnostic power than macular thickness parameters and it has been proved to be a useful method for glaucoma diagnosis and has potential for tracking glaucoma progression [6].

A newer generation swept-source OCT (DRI-OCT1 Atlantis system, Topcon, Tokyo, Japan) has an automated algorithm for segmenting macular inner retinal layers, and provides the thicknesses of the peripapillary RNFL and the ganglion cell inner plexiform layer in the macular area [7].

\section{Patients and Methods}

\section{Study population}

This is a comparative cross-sectional study was conducted at Mansoura ophthalmic center, Mansoura university. This study protocol was approved by Mansoura medical research ethics committee, faculty of medicine, Mansoura university (code number: MS/17.3.73) and informed consent obtained from each participant in the study after assuring confidentiality.

Inclusion criteria were included: POAG patients age above 40 years, best corrected visual acuity $\geq 6 / 60$, refractive error within \pm 6.0 diopters equivalent sphere and within \pm 3.0 diopters astigmatism or less than 2.0 diopter anisometropia, open anterior chamber angle on gonioscopy, glaucomatous changes on the Humphrey 24-2 visual field test, evidence of glaucomatous optic nerve head damage. While control subjects included no history or evidence of ocular disease, surgery or laser, no family history of glaucoma, intraocular pressure of $21 \mathrm{mmHg}$ or less, normal optic nerve head appearance based on clinical stereoscopic examination without visual field deterioration.

Exclusion criteria included: Previous intraocular surgery or laser therapy, possible consistently unreliable visual fields (defined as a false negative $>33 \%$, false positive $>33 \%$ and fixation losses $>20 \%$ ) were excluded from the study, possible neurological field loss were also excluded, angle closure glaucoma and secondary glaucoma, evidence of vitro-retinal disease or diabetic retinopathy, opacities of the optic media such as cataract and low quality image obtained with OCT, contraindication of pupil dilatation.

\section{Ocular examination}

All subjects underwent an ophthalmic examination including measurement of the BCVA using Snellen chart and converted to log MAR, measurement of IOP using Goldmann applanation tonometer, assessment of the anterior segment using slit lamp biomicroscopy (Haag Streit BP 900) (Haag-Streit, Koeniz, Switzerland), pupillary dilatation performed with mydriacyl $1 \%$ eye drops, fundus examination using a Volk lens 90 diopter, assessment of anterior chamber angle using Goldmann three mirror goniolens.

\section{Visual field testing}

The patients underwent Central 24-2 full threshold automated static perimetry by Humphrey (2003 Carl Zeiss Meditec, Germany). Reliable VF included fixation loss $\leq 20 \%$, false-positive rate $\leq 15 \%$ and false-negative rate $\leq 33 \%$. VF defects were defined as glaucomatous by either an abnormal report on the glaucoma hemifield test or a pattern standard deviation (PSD) of $<5 \%$ of the normal reference (confirmed by two consecutive tests).

\section{Optical coherence tomography examination}

Swept source optic coherence tomography (DRI-OCT1, Atlantis system, Topcon, Tokyo, Japan) used for evaluation the following: Peripapillary RNFL, total macular thickness and macular ganglion cell-inner plexiform layer.

Technique of OCT scanning was done as follows: Mydriatic eye drops were used to achieve as much pupil dilatation as we can to assure maximal OCT signal and analysis. The chair height, chin rest and imaging machine were adjusted to approximate position, the patient's chin was positioned in the chin rest, the patient was asked to fixate on a target inside the instrument. In cases of poor vision with difficult fixation, an external fixation target was used.

OCT scanning was performed for optic disc and macula at least 2 good quality images were taken then averaged for analysis to confirm reproducible results, after that, starting OCT examination by selecting mod from the main menu of the instrument for optic disc and macula regions centered $6 \times 6 \mathrm{~mm}$ cube, by the same technique as before the patient was asked to fixate the new target then start scanning and we chose the good quality images with high resolution (Figure 1 and 2).

\section{Statistical analysis}

Data were analyzed using IBM SPSS software package version 20.0 (Armonk, NY: IBM Corp). Qualitative data were described using number and percent. The Kolmogorov-Smirnov test was used to verify the normality of distribution Quantitative data were presented as mean \pm SD for parametric data and median (min-max) for non-parametric data. The two groups were compared with Student $t$ test for parametric data and Mann Whitney test for non-parametric data. Pearson (parametric) and Spearman (non-parametric) correlation were used to correlate continuous data. The level of significance is fixed at $5 \%$ level ( $p$-value). 


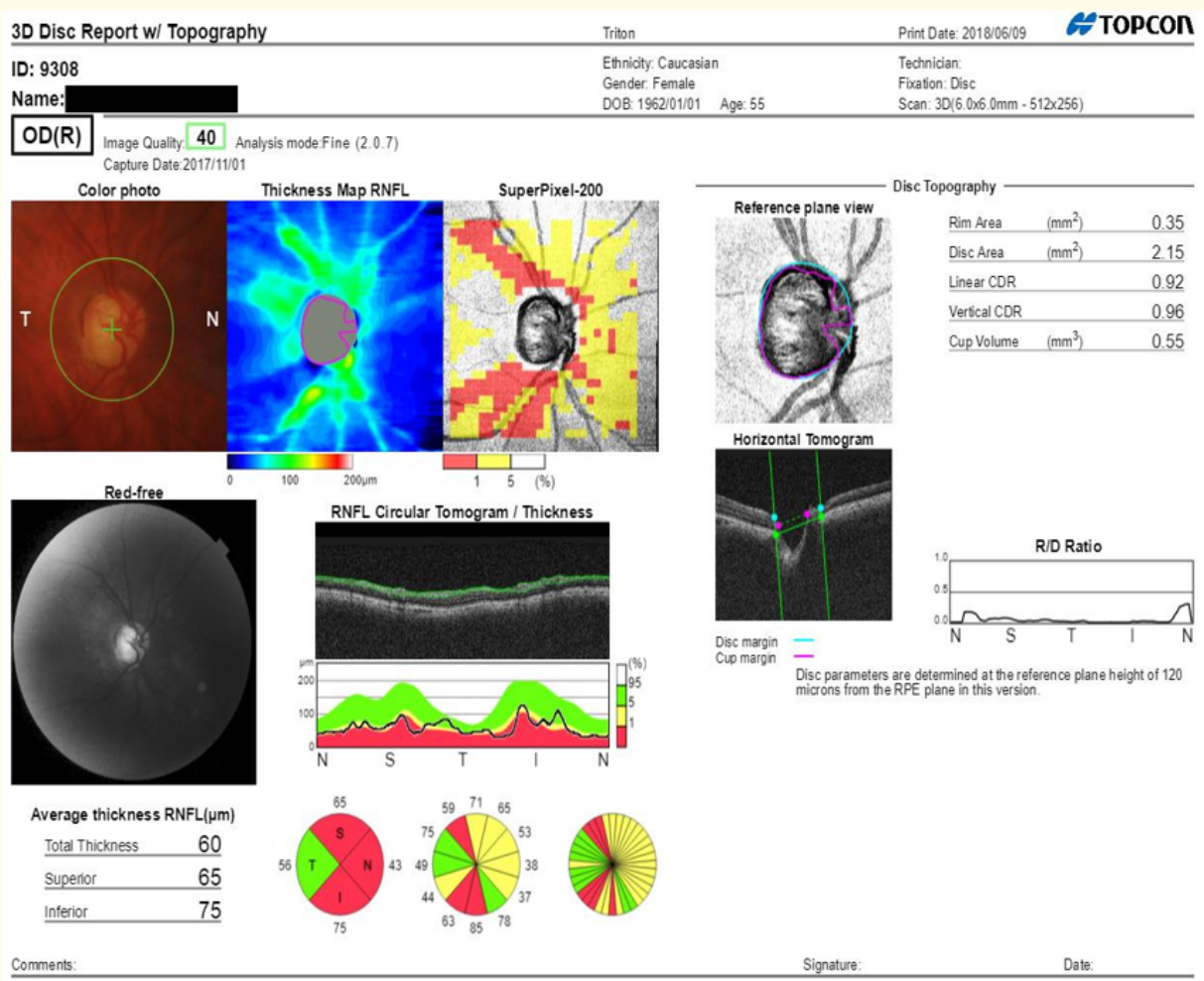

Figure 1: Print out of SS-OCT scan of same patient showing peripapillary RNFL thickness map of right eye of POAG patient.

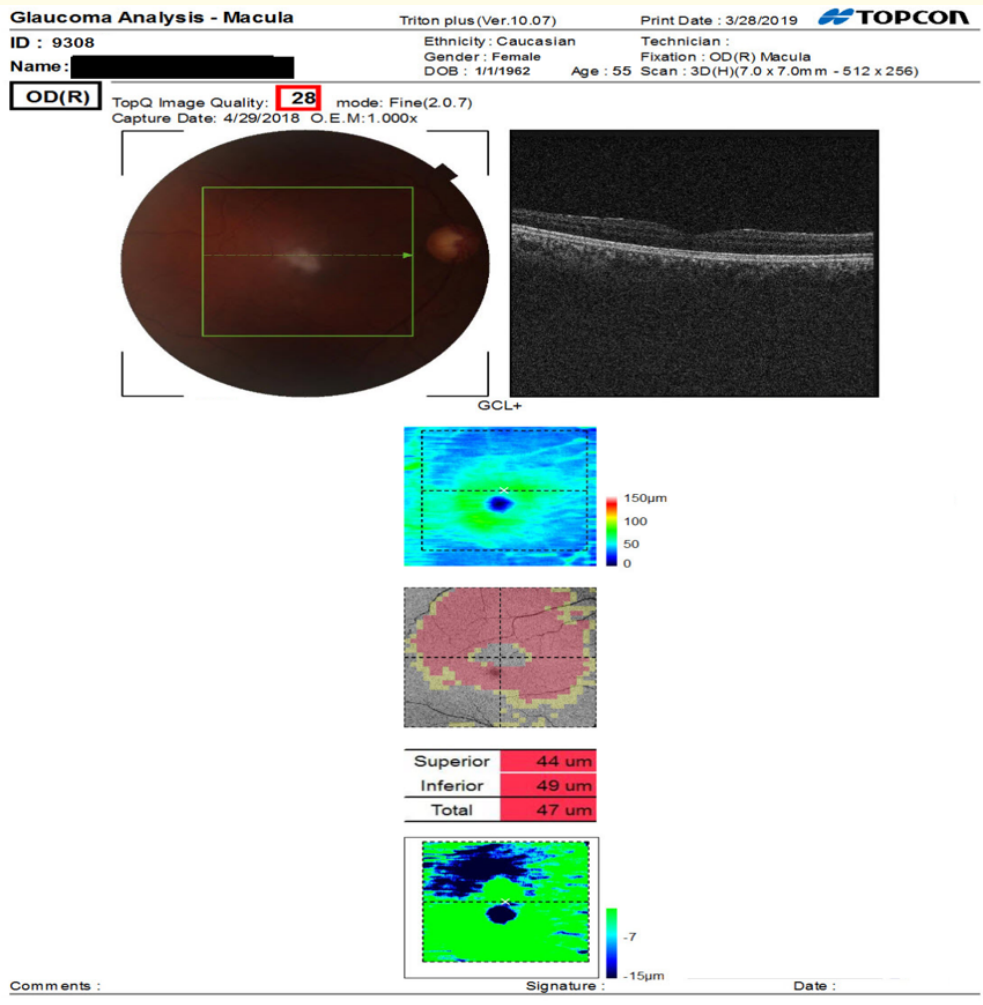

Figure 2: Print out of SS-OCT scan of same patient showing Macular GC-IPL thickness map of right eye of POAG patient. 


\section{Results}

Eighty eyes of 80 subjects including 40 eyes with POAG which were classified according to disease severity into 12 eyes with mild glaucoma, 13 eyes with moderate glaucoma, 15 eyes with severe glaucoma and 40 eyes of 40 healthy volunteers were included in this study.

The mean age of the patients with POAG was $58.20 \pm 9.12$ years; 26 eyes $(65.0 \%)$ were male and 14 eyes $(35.0 \%)$ were female. The mean age of control subjects was $54.10 \pm 9.11$ years. Comparison between the clinical characteristics of the study groups (spherical equivalent, IOP in $\mathrm{mmHg}$, MD in $\mathrm{db}$ ) revealed that no statistically significant difference was found between normal and glaucomatous eyes. A statistically significant difference of BCVA, IOP, MD was detected between both groups $(\mathrm{p}<0.001)$.

Mean macular GCIPL thicknesses had significantly decreased in the glaucoma patients $57.23 \pm 6.72$ um compared to the controls $72.33 \pm 3.17$ um with $\mathrm{p}$ value $(\mathrm{p}<0.001)$ as shown in table 1 and showed that the mean of macular GC-IPL thickness were significantly decrease in severe glaucoma eyes $52.88 \pm 3.17$ um, moderate glaucoma $61.12 \pm 5.04 \mathrm{um}$, mild glaucoma $67.00 \pm 4.40 \mathrm{um}$, in comparison with control eyes $72.33 \pm 3.17$ um $(\mathrm{p}<0.001)$ for all pairwise comparison as shown in table 2 and figure 3.

\begin{tabular}{|c|c|c|c|c|}
\hline $\begin{array}{c}\text { Macular GC-IPL } \\
\text { thickness }(\boldsymbol{\mu m})\end{array}$ & $\begin{array}{c}\text { Patients } \\
(\mathbf{n = 4 0 )}\end{array}$ & $\begin{array}{c}\text { Control } \\
(\mathbf{n = 4 0 )}\end{array}$ & T & P \\
\cline { 1 - 3 } Min. - Max. & $43.0-67.0$ & $71.0-82.0$ & \multirow{2}{*}{$15.263^{*}$} & $<0.001^{*}$ \\
\cline { 1 - 3 } \pm Mean SD. & $57.23 \pm 6.72$ & $72.33 \pm 3.17$ & & \\
\cline { 1 - 3 } Median & 58.0 & 76.0 & & \\
\hline
\end{tabular}

Table 1: Comparison between the studied groups according to Macular GC-IPL thickness $(\mu \mathrm{m})$.

t: Student t-test.

p: p value for comparison between the two studied groups.

$*$ : Statistically significant at $p \leq 0.05$.

Macular GC-IPL thickness: Macular ganglion cell inner plexiform layer.

The present study showed that POAG patients had significantly thinner peripapillary RNFL thickness $75.47 \pm 10.90$ um when compared with controls $103.0 \pm 4.32 \mathrm{um}(\mathrm{p}<0.001)$ as shown in table 3 and showed that the mean of peripapillary RNFL thickness were significantly thinner in severe glaucoma eyes $65.21 \pm 7.06 \mathrm{um}$, moderate glaucoma $80.12 \pm 6.01 \mathrm{um}$, mild glaucoma $91.00 \pm 7.27$ um, in comparison with control eyes $103.0 \pm 4.32$ um ( $p<0.001)$, for all pairwise comparison as shown in table 4 and figure 4 .

\begin{tabular}{|c|c|c|c|c|c|c|}
\hline & \multicolumn{3}{|c|}{ Patients $(n=40)$} & \multirow{2}{*}{$\begin{array}{l}\text { Control } \\
(\mathrm{n}=\mathbf{4 0})\end{array}$} & \multirow[b]{2}{*}{$\mathbf{F}$} & \multirow[b]{2}{*}{$\mathbf{P}$} \\
\hline & $\begin{array}{c}\text { Mild } \\
(n=12)\end{array}$ & $\begin{array}{c}\text { Moderate } \\
(n=13)\end{array}$ & $\begin{array}{c}\text { Severe } \\
(n=15)\end{array}$ & & & \\
\hline \multirow{2}{*}{$\begin{array}{l}\text { Macular } \\
\text { GC-IPL } \\
(\mu \mathrm{m})\end{array}$} & $\begin{array}{c}67.00 \pm \\
4.40\end{array}$ & $\begin{array}{l}61.12 \pm \\
5.04\end{array}$ & $\begin{array}{c}52.88 \pm \\
3.17\end{array}$ & $\begin{array}{c}72.33 \pm \\
3.17\end{array}$ & 82.521 & $\begin{array}{c}< \\
0.001 *\end{array}$ \\
\hline & \multicolumn{4}{|c|}{$\begin{aligned} \mathrm{P} 1<0.001^{*}, \mathrm{P} 2 & <0.001, \mathrm{P} 3<0.001^{*} \\
\mathrm{P} 4 & <0.001^{*}\end{aligned}$} & & \\
\hline
\end{tabular}

Table 2: Comparison between the studied sub-groups according to Macular GC-IPL thickness $(\mu \mathrm{m})$.

\section{F: F for ANOVA test.}

$\mathrm{p}$ : $\mathrm{p}$ value for comparing between the studied groups.

$\mathrm{p}_{1}$ : $\mathrm{p}$ value for comparing between control and mild.

$\mathrm{p}_{2}$ : $\mathrm{p}$ value for comparing between mild and moderate.

$\mathrm{p}_{3}$ : $\mathrm{p}$ value for comparing between mild and severe.

$\mathrm{p}_{4}$ : $\mathrm{p}$ value for comparing between moderate and severe.

*: Statistically significant at $\mathrm{p} \leq 0.05$.

Macular GC-IPL thickness: Macular ganglion cell inner plexiform layer.

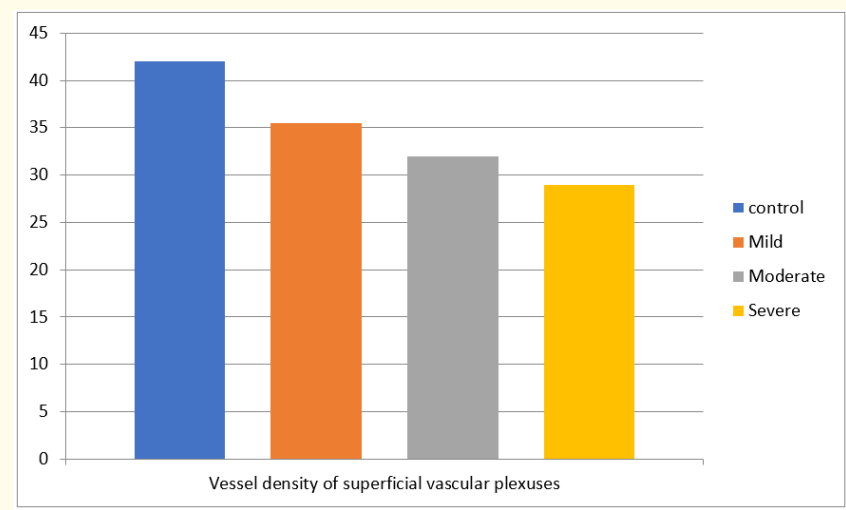

Figure 3: Macular GC-IPL thickness $(\mu \mathrm{m})$ among the studied groups.

\section{Discussion}

Optical coherence tomography has a reliable glaucoma detection capability and has been widely used for quantitative structural evaluation in glaucoma. which is able to provide a measurement of retinal thickness is commonly used for monitoring glaucomatous progression [1].

Studies have shown that the thickness of the macular inner retinal layer as measured using OCT is useful for the diagnosis of early glaucoma [8] and for evaluating glaucoma progression [9]. A 


\begin{tabular}{|c|c|c|c|c|}
\hline $\begin{array}{c}\text { Peripapillary } \\
\text { RNFL }(\boldsymbol{\mu m})\end{array}$ & $\begin{array}{c}\text { Patients } \\
(\mathbf{n}=\mathbf{4 0})\end{array}$ & $\begin{array}{c}\text { Control } \\
(\mathbf{n = 4 0 )}\end{array}$ & $\mathbf{t}$ & $\mathbf{p}$ \\
\cline { 1 - 3 } Min. - Max. & $56.0-94.0$ & $97.0-107.0$ & \multirow{2}{*}{$14.725^{*}$} & $<0.001^{*}$ \\
\cline { 1 - 2 } Mean \pm SD. & $75.47 \pm 10.90$ & $103.0 \pm 4.32$ & & \\
\cline { 1 - 2 } Median & 76.0 & 103.0 & & \\
\hline
\end{tabular}

Table 3: Comparison between the studied groups according to peripapillary RNFL thickness $(\mu \mathrm{m})$. t: Student t-test.

$\mathrm{p}$ : $\mathrm{p}$ value for comparison between the two studied groups.

*: Statistically significant at $\mathrm{p} \leq 0.05$.

Peripapillary RNFL: Peripapillary retinal nerve fiber layer.

\begin{tabular}{|c|c|c|c|c|c|c|}
\hline & \multicolumn{3}{|c|}{ Patients $(n=40)$} & \multirow{2}{*}{$\begin{array}{l}\text { Control } \\
(n=40)\end{array}$} & \multirow[b]{2}{*}{$\mathbf{F}$} & \multirow[b]{2}{*}{$\mathbf{P}$} \\
\hline & $\begin{array}{c}\text { Mild } \\
(n=12)\end{array}$ & $\begin{array}{c}\text { Moderate } \\
(n=13)\end{array}$ & $\begin{array}{c}\text { Severe } \\
(n=15)\end{array}$ & & & \\
\hline $\begin{array}{l}\text { Peripapillary } \\
\text { RNFL }(\mu \mathrm{m})\end{array}$ & $\begin{array}{c}91.00 \pm \\
5.27\end{array}$ & $\begin{array}{l}80.12 \\
\pm 6.01\end{array}$ & $\begin{array}{c}65.21 \pm \\
7.06\end{array}$ & $\begin{array}{c}103.0 \pm \\
4.32\end{array}$ & $\begin{array}{l}121 . \\
698\end{array}$ & $\begin{array}{c}< \\
0.001 *\end{array}$ \\
\hline Significance & \multicolumn{4}{|c|}{$\begin{array}{c}\mathrm{P}_{1}<0.001^{*}, \mathrm{P}_{2}<0.001, \mathrm{p}_{3}<0.001 * \\
\mathrm{p}_{4}<0.001\end{array}$} & & \\
\hline
\end{tabular}

Table 4: Comparison between the studied sub groups according to Peripapillary RNFL $(\mu \mathrm{m})$.

F: $F$ for ANOVA testp: $p$ value for comparing between the studied groups.

$\mathrm{p}_{1}$ : $\mathrm{p}$ value for comparing between control and mild.

$\mathrm{p}_{2}$ : value for comparing between mild and moderate.

$\mathrm{p}_{3}: \mathrm{p}$ value for comparing between mild and severe.

$\mathrm{p}_{4}$ : $\mathrm{p}$ value for comparing between moderate and severe.

*: Statistically significant at $\mathrm{p} \leq 0.05$.

Peripapillary RNFL: Peripapillary retinal nerve fiber layer.

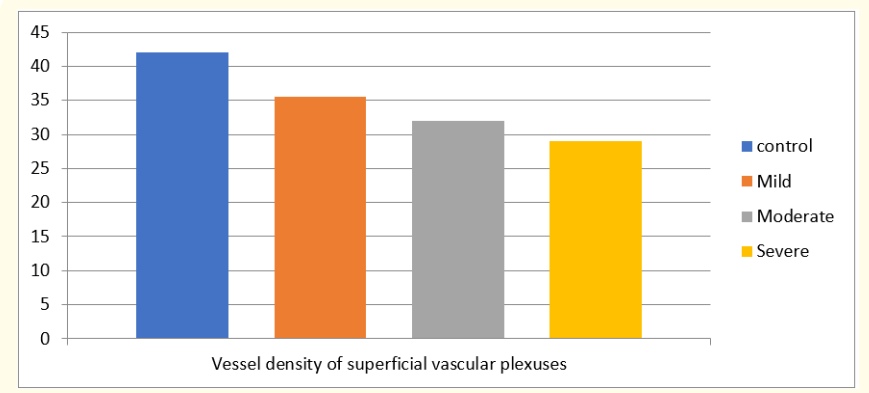

Figure 4: Peripapillary RNFL $(\mu \mathrm{m})$ among the studied groups.

newer generation swept-source OCT has an automated algorithm for segmenting macular inner retinal layers and provides the thick- nesses of the GCL plus inner plexiform layer in the macular area. In addition, SS-OCT penetrates deeper into the tissue and provides high-resolution images [7].

In present study, comparison between patients with POAG and controls regarding the demographic characteristics found that patients with POAG had significantly lower VF MD $(-3.49 \pm 1.88$ vs. $0.60 \pm 0.10 ; p=0.0001^{*}$ ) when compared with controls. This is in agreement with the study of Hasegawa., et al.

Regarding the comparison between retinal nerve fiber measurements in patients with different stages of glaucoma and controls, the present study found patients with early disease had significantly thicker average RNFL thickness measurements when compared with patients with mild, moderate and severe disease $(103.0 \pm 4.32$ $\mu \mathrm{m}, 91.00 \pm 7.27 \mu \mathrm{m}, 80.12 \pm 6.01 \mu \mathrm{m}$ and $65.21 \pm 7.06$ respectively). This is in agreement with the study of Mansoori., et al. who assessed the utility of SD-OC to distinguish normal eyes from those with early glaucoma in Asian Indian eyes. The mean RNFL thickness in healthy subjects and patients with early glaucoma were $105.7 \pm 5.1 \mu \mathrm{m}$ and $90.7 \pm 7.5 \mu \mathrm{m}$, respectively $(\mathrm{p}=0.001)$.

Kaw., et al. [5] in their study aimed to compare SD-OCT evaluation of RNFL thickness in normal controls and POA glaucoma of various stages and found that normal patients had the thickest RNFL thickness when compared with patients while the increased glaucoma severity was associated with thinner RNFL.

The present study is consistent with the study of Akil., et al [6]. In their study, there was significant difference between patients with glaucoma and age-matched healthy controls in terms of glaucoma parameters ( $p<0.05$ ), mean RNFL thickness was $69.3 \pm 1.0$ $\mu \mathrm{m}, \mathrm{GC}$-IP layer thickness was $63.8 \pm 11.04 \mu \mathrm{m}$, VF MD was $-6.4 \pm$ $5.2 \mathrm{~dB}$.

In this study, it was shown that glaucoma patients had significantly lower peripapillary RNFL measurements when compared with controls (91.00 \pm 7.27 um vs $106.80 \pm 6.58$ um; $\mathrm{p}<0.001)$, This in accordance with the study of Elbendary and Mohamed Helal [7] who evaluated the role of SD-OCT in different stages of glaucoma and found similar results.

The present study is in agreement with the study of Golzan., et al. [8], who assessed RNFL thickness in patients with glaucoma and healthy controls. In their study, patients with glaucoma had significantly lower RNFL thickness when compared with controls (87 \pm $26 \mu \mathrm{m}$ vs $111 \pm 15 \mu \mathrm{m}, \mathrm{p}<0.0001)$. 
Current study consistent with the study of Hammel., et al., revealed that there was significant decrease GCIPL thickness compared to controls healthy eyes. Moreover, as significant change in macular GCIPL was detectable in severe glaucoma eyes, imaging may provide important information on whether a patient is progressing at all stages of glaucoma, including advanced disease.

The present study is consistent with the study of Takusagawa., et al. [9] that found that GCC thickness in the glaucoma group were significantly lower than in the normal group $(\mathrm{P}<0.001)$. Structural OCT studies have shown that the macular GCC thickness and other measures of RGC volume are reduced in patients with glaucoma and focal loss of macular GCC is a good predictor of VF conversion and progression.

The present study is in agreement with the study of Triolo., et al. [10] showed that GC-IP layer thickness and peripapillary RNFL thickness, significantly decreased in the glaucoma group compared to controls $(\mathrm{P}<0.001)$.

\section{Conclusion}

Swept-source OCT revealed significant decrease in peripapillary RNFL thickness and macular GC-IP layer thickness in POAG patients, which subsequently may afford an indicator whether a patient is progressing at all stages of glaucoma.

\section{Declarations}

Ethics approval and consent to participation; This observational cross section study was approved by the ethics committee of Faculty of medicine, Mansoura university (Registration Number: MS/17.3.73, Date: 8/4/2017) and adhered to the tents of Declaration of Helsinki. All subjects provided written informed consent prior to study participation.

\section{Consent for Publication}

Not applicable.

\section{Availability of Data and Materials}

Data are available upon request.

\section{Competing of Interests}

The authors declare that they have no conflict of interests.

\section{Funding}

Authors have not declared a specific grant from this research from any funding agency in the public, commercial.

\section{Authors Contributions}

GA and ED designed the study, ED and AM performed examinations of individuals, MH prepared and carried out the analysis, AM and $\mathrm{AA}$ interpreted and discussed the results and wrote the first version of the manuscript. All authors read and approved the final manuscript.

\section{Bibliography}

1. Na JH., et al. "Detection of glaucomatous progression by spectral-domain optical coherence tomography". Ophthalmology 120.7 (2013): 1388-1395.

2. Wu H., et al. "Diagnostic capability of spectral-domain optical coherence tomography for glaucoma". American Journal of Ophthalmology 153.5 (2015): 815-826.

3. Yu M., et al. "Risk of visual field progression in glaucoma patients with progressive retinal nerve fiber layer thinning a 5-year prospective study". Ophthalmology 123.6 (2016): 1-10.

4. Tomoko H., et al. "Microcystic inner nuclear layer changes and retinal nerve fiber layer defects in eyes with glaucoma”. PLoS One 10.6 (2015): e0130175.

5. Kaw SMG., et al. "Correlation of average RNFL thickness using the Stratus OCT with the perimetric staging of glaucoma". Philippine Journal of Ophthalmology 37 (2012): 19-23.

6. Akil H., et al. "Swept-source OCT angiography imaging of the macular capillary network in glaucoma". British Journal of Ophthalmology 102 (2018): 515-519.

7. Elbendary AM and Mohamed HR. "Discriminating ability of spectral domain optical coherence tomography in different stages of glaucoma". Saudi Journal of Ophthalmology 27.1 (2013): 19-24.

8. Golzan SM., et al. "Correlation of retinal nerve fibre layer thickness and spontaneous retinal venous pulsations in glaucoma and normal controls". PLoS One 10.6 (2015): 128-233.

9. Takusagawa HL., et al. "Projection-resolved optical coherence tomography angiography of macular retinal circulation in glaucoma". Ophthalmology 124.11 (2017): 1589-1599.

10. Triolo G., et al. "Optical coherence tomography angiography macular and peripapillary vessel perfusion density in healthy subjects, glaucoma suspects, and glaucoma patients". Investigative Ophthalmology and Visual Science 58 (2017): 57135722. 
Assets from publication with us

- Prompt Acknowledgement after receiving the article

- Thorough Double blinded peer review

- Rapid Publication

- Issue of Publication Certificate

- High visibility of your Published work

Website: www.actascientific.com/

Submit Article: www.actascientific.com/submission.php

Email us: editor@actascientific.com

Contact us: +919182824667 